\title{
OPERATIONAL ANALYSIS IN SUPPORT OF ARMED FORCES TRANSFORMATION: THE ROLE OF ORGANIZATIONAL CULTURE
}

\author{
Evgeni MANEV
}

\begin{abstract}
This article starts with presenting a very comprehensive review of the process of armed forces transformation. The proposed framework offers a clear vision for the main directions and parameters of armed forces transformation. It provides opportunities to include lessons learned and to develop strategies for dealing with the military reform. In order to accomplish optimal reforms, these strategies have to be studied carefully and after that, based on the result, planned and implemented. Certainly, all capacity of the nation must be harnessed to that process, including the operational analysis approach. In performing operational analysis, the author considers a very important aspect - the role of organizational culture. The study performed by the author helps him conclude that organizational culture change has to go first and "tow" operational analysis and transformation processes ahead. Therefore, the role of organizational culture can be defined as advanced, leading and determining.
\end{abstract}

Keywords: Armed Forces transformation, operational analysis, organizational culture

Many definitions of transformation have been used in the literature and in practice. For illustrative purposes we will review some of them.

Transformation is a continuous and focused change, in large scale, often undertaken with strategic goal in order to create or enhance the advantages that strengthen our competitiveness, or to meet current or new advantages of the competitor. ${ }^{1}$

Some conclusions can be drawn from this definition:

- Transformation is a process focused on controllable change of the organization. Hence, the general organizational theory can be applied to the organizational change during transformation.

- The duration of this kind of change is longer than other organizational changes. 
- Transformation differs from the other changes by a larger scale of simultaneous changes within the organization.

- Transformation is focused on strategic goals in organizational change for obtaining or preserving competitiveness in terms of competition.

The following U.S. Armed Forces definition derives from a previous general definition of transformation adopted by the Department of Defense according to which the transformation is a "process that reflects the changing nature of military competition and collaboration by new combinations of concepts, capabilities, human resource and organizational elements for using our advantages and defending our vulnerability from asymmetric threats in the name of preserving our strategic position and from that the peace and stability in the world." 2

The following specific points can be stressed on:

- Transformation is a process of objective reflection of the modern challenges to military collaboration and competition. It is a process of simultaneous change of:

- Concepts;

- Human resources;

- Operational capabilities; and

- Organizations.

- The goal of competition that is realized by obtaining advantages over the competitor is avoiding or diminishing asymmetric threats.

- Competitiveness is required for defending the vulnerability of the United States from asymmetric threats in order to:

- Keep the U.S. in a strategic position;

$\circ$ Preserve peace and stability in the world.

We have used the term transformation very often. "Even we have no common recognized and shared definition for that term and different nuances of it we well know what it means. We accept the transformation as a process that is focused on the change of the system, which is motivated by the necessity of its adaptation towards new parameters of the environment ... the transformation of the armed forces is ... a means that we use in order to make our policy more effective and to deal with the security challenges. The transformation ... requires us to act simultaneously in two interconnected and prioritized directions - modernization and build up of professional armed forces ... the transformation is ... a process of continued development, changing the way of thinking and our capabilities ... The goals we hope to achieve by it re- 
quired us to build up a new strategic culture and to establish a new strategic approach towards the security and defense issues."3

Several conclusions could be made from the definition given above:

- Transformation is purposeful and controllable change of the organizational systems.

- The goal of that change is adaptation towards the new realities of the environment. The adaptation is a response to the challenges that derive from the current changes in the same environment.

- The armed forces transformation is a means for more effective policy making in response to the challenges.

- The priorities of the Bulgarian armed forces are defined as follows:

- Modernization; and

- Building up of professional armed forces.

- Transformation is a continuous process of upgrading and developing of:

- The way of thinking about security, education, training and armed force employment;

- New operational capabilities.

- The goal of transformation is to build up new strategic culture and new approach towards the security and defense issues.

Considering these three definitions, after a brief analysis, one can conclude that the main goal of transformation is to achieve a strategic advantage over the competitor (the risks and threats) now and in the future. The human factor is put in the centre of transformation, as well as the new doctrines, the increasing operational capabilities and the adequate organizational structures. Key factors are the new operational capabilities and the new strategic culture of the armed forces.

The operational capabilities of the armed forces are quantitative and qualitative indicators that characterize the potential and abilities of the armed forces to carry out specific combat and other missions in certain environment. They are formed by:

- A human factor that is defined by its main elements:

- Education that gives a fundamental knowledge for the specific professional area;

- Qualification that is knowledge, skills and abilities for the specific job position;

- Training that gives specific skills and routine tailored to the particular job position; 
- Organizational culture that gives a system of values and beliefs commonly accepted and shared in the organization. This system of values defines initial positions for evaluating what is right and wrong within the organization, motivates behaviors and assessments for organizational prosperity.

- Material factors:

- Kind, type, quantity and technology level of the armament, material means, and infrastructure;

- Qualitative characteristics of the armament and material means.

- Non-material factors:

- Doctrines that define the processes that organizations need;

- The organizational structure of the armed forces and its units that has to provide effective mission performance in the future;

- The command, control and support systems of the organization in terms of legislation and sub-legislation matters;

- The level of preparedness of the staff - education, specialization, training, interoperability of the units, capabilities of unit replacement.

The context of armed forces operational capabilities shows that they depend mainly on combat potential and combat readiness of the units and staff quarters.

The combat potential of the troops is given by the capabilities that can be demonstrated in certain conditions. The indicator of combat potential includes three elements. The first one is the armament and equipment capability that has relatively constant magnitude in time. The second element is the human factor that demonstrates relatively more dynamic nature in time. The third factor is the organization, command and control structures of the units regarded as a complex of procedures and technological level of the equipment. The potential capabilities of units have variable quantitative magnitude in time and space frame. The "moment picture" reflects only the quantitative-qualitative factors of these units, in other words, staff and material capabilities at the moment.

Combat readiness of the units is a condition, from which they can accomplish specific tasks. It is defined by staffing, theoretical and practical preparation of the commanding officers, staff headquarters and manpower, effectiveness of the logistic support and correct understanding of the missions by commanders, headquarters and their capabilities for making the right decisions and predicting the environmental and situational changes. 
The armed forces capabilities have to be considered within the context of the necessity of successful accomplishment of the missions that the Bulgarian armed forces will carry out. We can discuss the required operational capabilities (ROC) within that framework. For example, ROC for a mission in a specific region and environment might be quite different from a mission in another region and environment. But, at the same time, they share similar ROC. For example, strategic air and sea lift for staff and equipment to the region of employment, mobility and autonomy of unit actions, etc.

This simple framework presents a clear vision for the main directions and parameters of the Bulgarian armed forces transformation. It provides opportunities to include lessons learned from the past and to develop strategies for dealing with the military reform. In order to accomplish optimal reforms, these strategies have to be researched carefully and after that, based on the result, planned and implemented. Certainly, all capacity of the nation must be harnessed to that process, including the operational analysis approach.

Operational analysis of all transformation activities is a complex process involving interconnected research work of the activities of the armed forces, the strategic political and military leadership. These are not isolated acts or activities performed by special operational analysis scientific units only. All scientific, administrative and military units should be involved in the process. The strategic political and military leadership of the Ministry of Defense (MoD) and the General Staff (GS) must organize the process of operational analysis. The combined approach has to include both institutional and functional principles. For that reason, operations research has to be carried out according to the MoD master plan that coordinates activities.

According to the definition of Morse and Kimball from the 1950s, "operations research is a scientific method of providing executive departments with a quantitative basis for decisions regarding the operations under their control."4 Therefore, the decisions are correct because they are based on data obtained by scientific methods. Needless to say, in order to apply the operations analysis decision-making approach a supportive corporate organizational culture adopted by the MoD and GS is needed. This is one of the new elements of organizational culture mentioned in the definition given above. Change of organizational culture is a difficult task, but the shortest way to achieve this is a knowledge improvement process that assumes three forms: education, specialized courses and practice (training). In order to reach that goal, it is required to know what the current culture is and what new culture we need, respectively operations analysis. When this assessment is ready, the plans for culture change must be ready too before initiating culture change. In the opposite case, the old organizational culture will oppose organizational change. It does not matter what the change might be. Change of the way of thinking means that we have to change the organizational culture in advance. In other words, this means to have change in advance of the 
organizational value system and based on that to change the organizational structures, procedures and behaviors that lead to the increase of organizational effectiveness. The bottom line is obtaining competitive advantage.

Figure 1 demonstrates the results from an empirical study of one of the aspects of organizational culture. The results enable the implementation of organizational culture theory for identification of the criteria for success of an organization. The researchcarried out in the period March-April of 2007 in some of the colleges of the MoDproves that the organizational culture has a decisive role for the prosperity of an organization. From the profile (see Figure 1) of the investigated aspect of the organizational culture - "Criteria for Success of the organization (CS)"- - the following observations can be made:

- The criteria for success attain the highest value in the quadrant of hierarchy culture, followed by the clan and adhocracy types of culture and reach the lowest value in the market type of culture. The values are decreasing by two points starting from hierarchy culture passing through clan and going to market culture; the value of the criteria there is seven points less than the value attained by the adhocracy culture and eleven points less than the one of the hierarchy type. The criteria having greater values are accepted better than those having lesser values in the organization;

- The criteria for success of the hierarchy culture have the greatest value. It means that the organization functions successfully if it operates according to well established rules, the job positions are specialized, everyone's merit for the success is valued, a strong hierarchical structure is established, the property does not belong to the employees and principles of responsibilities and objectiveness are applied. These characteristics are tailored with high effectiveness to wide range of organizations with main challenge to have effective, reliable, permanent and predictable production (element of national security). Till 1960s almost all management research publications assumed Webber's hierarchy as ideal organizational form due to its capabilities of providing stable, effective and high level interoperable products and services. $^{5}$

- The environment was relatively stable at that time and tasks and functions could be integrated and coordinated. The uniformity of products and services could be maintained and the employees could be controlled. The clear lines of decision-making authority, the standard rules and procedures, management and mechanisms for responsibilities are accepted as key elements for the success. 


\section{Flexibility and freedom of action}

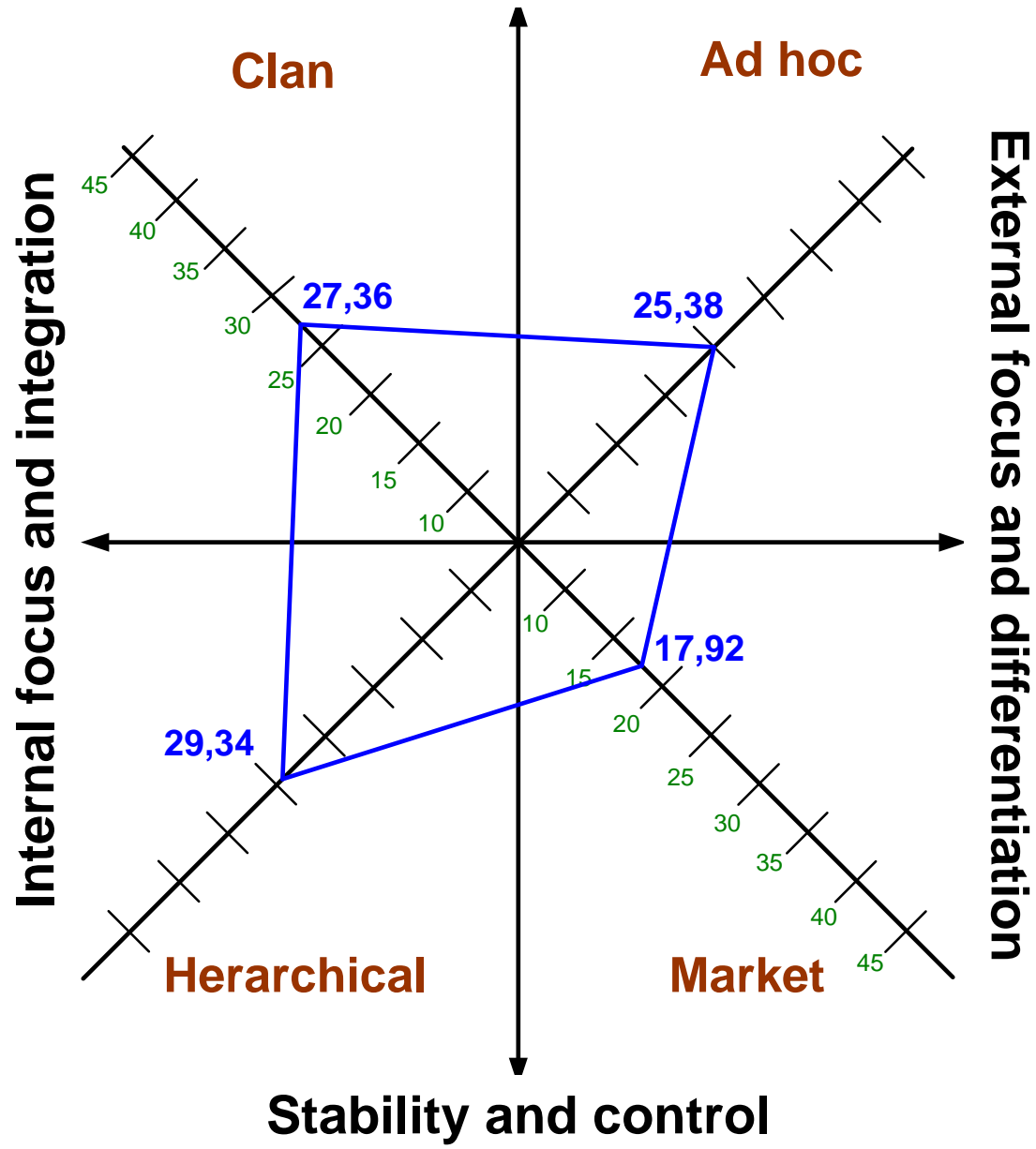

Figure 1: Profile of the Criteria for Success of the Unit of Military University from MOD.

The hierarchy culture is characterized by formal and structured job positions where the procedures require people to follow the rules. The effective leaders are those who are good in coordination and organization.

It is important to maintain a fluent working process of the organization. Long-term organizational goals are stability, predictability, and effectiveness. The formal rules are the glue that holds the organization together. The big number of standard proce- 
dures, the multilayer hierarchy levels and observing the rules prove that. The hierarchy culture can dominate even in small organizations.

- The CS of the clan culture rated second. Clan culture is characterized by shared values, goals, coherent participation, individual feelings, and "we the group members" feelings. It makes possible to create organizations like big families. They are more similar to a big family than to a company. Instead of hierarchy procedures or market competition, the typical clan characteristics are team work, involvement of the employees in the programs and also the corporate care for the employees. The main assumptions of the clan culture are as follows: the environment can be controlled better by team work, employees development and upgrade of the work environment are important, the clients are the best partners of the organization, the main task of the management is the growth of the employees and the facilitation of their participation, engagement and loyalty to the organization.

These characteristics are not new, but they were neglected for decades due to the adherence to McGregor's theories of human behavior. ${ }^{6}$ This brought to a visible success many Japanese companies that accepted and applied these principles successfully after World War Two. The United States and Western Europe took the idea in late 1970s-1980s. They found that the clan culture can create good conditions for the business. When the environment change is fast, long-term planning is difficult and the decision-making process is indefinite. In that case, the effective way of coordinating organizational performance is to provide sharing of the same values, beliefs and goals by every member of the organization.

The characteristics of the clan culture are as follows: minimum levels of management, informal control and self-control, the employees possess some property of the organization, team work, participation in the decision-making process and job rotation. This could explain why the modern organizations need clan culture.

The adhocracy culture ranked third considering the responses. When the developing world moved from industrial to information age, this new type of organizational culture appeared. It is an organizational form that is most responsive to the heavy turbulent and accelerating circumstances that characterize the $21^{\text {st }}$ century organizational world. With the rapid decrease of the time period when products and services are competitive, the adhocracy set of assumptions was developed. It differs from the other three forms of organizations. The assumptions are that innovative initiatives lead to success. These organizations are mainly in the business of new product development (in our case ROC) and in the preparation for the future. That is why the main concerns of the business are to support entrepreneurship, "leading edge" creativity and activity of organizational members. It is assumed that adaptation and innovation 
lead to more resources and success. This explains why the stress is put on creating vision for the future.

The word adhocracy derives from the Latin root "ad hoc", which means created for special purpose and relates to modern, specialized and dynamic organization. The adhocracies are also temporary organizations. They are characterized as a tent, not as palaces because they can be reconfigured fast when new circumstances appear. The main goal of adhocracy is to increase adaptation, agility, and creativity when uncertainty, ambiguity and information overload dominate our day-to-day life.

Often, ad hoc organization can be found in the space industry, the software companies, the movie industry, and the "think-thank" consulting companies. The most important challenge for these companies is to produce innovative products and services and to get adapted to the new opportunities fast. The ad hoc organizations have no center of power that differentiates them from the hierarchy and market organizations. Instead, the power in the organization is transferred from leader to leader or from group to group together with the current group mission. Risk taking, individuality, and predictable future expenses are highly valued in the organization. Almost every member of the adhocracy is involved in production (mission), clients, research and development of the organization. For example, each mission is regarded as an independent project and ad hoc organization is created for it. When the project is accomplished, the organizational structure is decommissioned. This way of creating organizations is applied to defense missions, peace keeping or enforcement and other military tasks. Therefore, it is advisable to create and maintain such a culture in military organizations.

There are some sub-organizations that are dominated by ad hoc culture and their characteristics are as fallows: lack of organizational structure (the dynamics of the environment is so fast that establishment of organizational structure is not possible), the job places are temporary (temporary roles of staff are assigned according to the situations), the employees are encouraged to make innovative decisions and to generate new ideas for serving the clients. Adhocracy is also characterized as a dynamic, entrepreneurial and creative job place. Vision, innovation and operation in a risky environment are regarded as effective leadership. The glue that holds the organization together is an engagement to experimentation and innovation. The goal is maintaining the leading position in the areas of knowledge, products and services (in our case ROC). It is important to possess readiness for change and meeting new challenges. The long-term goals of the organizations are rapid growth and obtaining of new resources (in the case under consideration higher level of security). Success is defined as unique and original production and services that is accepted as competitive capabilities. 
The rating of the market culture is the lowest. The term market is not a synonym of market function or of the client on the market. It is viewed as an organization that functions as a market in itself. The organization is focused on the environment instead on the internal affairs. It is focused on transactions with external clients and procurement mainly. The difference between the hierarchy culture, where rules maintain the internal control, specialized jobs and centralized decisions are applied, and the market culture is that the market is driven by the market economy mechanisms, mainly monetary exchange. The bottom line is profitability, the share in the market niche, expanding goals and stable client mass. It is not surprising that the main values dominating the market organizations are high competitiveness and productivity. Competitiveness and productivity are achieved by means of a strong focus on the external positioning of the organization and the management.

These main assumptions are adopted by the market culture as a result of functioning in a non-favorable environment, growing demands of the clients and, in terms of preserving its values the organization is driven to grow its competitive positions. This is the reason why the main concerns of the management are to move the organization towards higher productiveness, results and success. The accepted idea is that a clear vision and aggressive strategy lead to productiveness and profit. Or, said in other words, the market organizations do not care about holding their positions, they let it to their competitor. They are marching forward, conquering new positions and chasing their goals all the time.

The market culture is a result-oriented culture. The leaders are tenacious drivers for obtaining new ROC. They are hard and seeking persons. The glue that holds the organization together is the focus on profit. The long-term concerns are maintaining and obtaining new competitive capabilities and achieving a broader package of goals and strategies. The success is defined by a market niche and market penetration that belongs to the organization. It is important for the organizational competitiveness to beat the competitors and to be a market leader.

One can conclude from the analyses provided that the four types of culture criteria are relatively balanced, besides their differences. This fact shows that the organization is at its mature stage of development and it is able to meet the full spectrum of challenges within the four types of culture, based on its operational capabilities and an adequate evaluation according to the adopted culture criteria.

As has been already mentioned, it is clear that the application of the organizational culture approach requires a framework to be defined in order to have a specific and faster move towards the new ROC. This framework is defined by political directives (goals), armed forces mission requirements and resource limitations. The framework provides basis for operational analysis that provides quantitative data necessary for 
the ROC decision-making process. It means that decisions are made in terms of what ROC will be developed in full scale, what will be developed in a limited scale and what will be obtained by the collective defense system. The preparation of the armed forces for participation in missions has to be organized based on these decisions, including educational and special courses programs at the military universities and colleges. Besides, the research programs of the scientific organizations and military universities have to be tailored to the ROC. Based on the ROC plans, plans for operational analysis and organizational culture change have to be developed in order to support armed forces transformation.

Based on what has already been elaborated, we can summarize and conclude the role of organizational culture change process in the armed forces transformation process.

- Considering that transformation is a strategic change that helps in acquiring new competitive capabilities in terms of threats as said in the definition of transformation, a new approach is required, a new way of thinking or even some definitions directly stipulate the establishment of a new culture. This puts at the first and most important place the organizational culture. It can be explained by the fact that the members of the organization think and assess things within the organizational value system framework. Hence, the process of building up future plans, including ROC plans, will reflect the implemented in them organizational visions, beliefs of what is right and wrong, success and failure; these are the elements of the organizational culture. Therefore, without a culture change, change in the way of thinking is not possible. Without changing the way of thinking, development of new plans for future competitive advantages is not possible. It makes the leading role of organizational culture change mandatory. Even more, culture change has to be put in the priority list. It has to be done in advance and in coordination during the process of transformation. In other words, organizational change has to go first and "tow" operational analysis and transformation processes ahead. Hence, the role of organizational culture can be defined as advanced, leading and determining.

- Even more, organizational culture is the all-embracing and the most general part that incorporates the process of transformation and people accept it right, on time, necessary, and the most important matter that should be done as it is done. Hence, the role of the organizational culture is to involve and unite the organization around transformation.

- Organizational culture provides the assumptions for the right criteria for success of the organization. Through the culture prism, people make their assessment for right and wrong activities, positive and negative results, success or failure of the organization. Hence, the accepted values of a certain or- 
ganizational culture play the role of criteria for organizational evaluation of success.

Finally, we can summarize that organizational culture is an important element of the effective organization for obtaining ROC. It is also a powerful leverage for increasing the effectiveness of the organizational functioning that should be taken into account during operational analysis and the transformation process of the armed forces.

\section{Notes:}

1 John J. Garstka, The Concept of Transformation, Its Reflection to the Political and Military NATO Structures and Some Aspects of the Reform, 2005.

2 Garstka, The Concept of Transformation.

3 Vesselin Bliznakov, Defense and Security Policy of the Republic of Bulgaria - Priorities and Challenges during 2006, Lecture at the Atlantic club, Sofia, 23 January 2006.

4 Philip M. Morse and George E. Kimball, Methods of Operations Research (New York: John Wiley, 1951).

5 Max Weber, The Theory of Social and Economic Organization, translated by A. M. Henderson \& Talcott Parsons (The Free Press, 1947).

6 Gary Heil, Warren Bennis, and Deborah C. Stephens, Douglas McGregor, Revisited: Managing the Human Side of the Enterprise (Wiley, 2000).

Major-General EVGENI MANEV is Commandant of "G.S. Rakovski" Defence and Staff College in Sofia, Bulgaria. He is graduate of the Bulgarian Air Force Academy, the "G.S. Rakovski" Defence and Staff College, and the U.S. Air War College at Maxwell Air Force Base, Alabama. He has a distinguished career of a fighter pilot and commander at all levels in the Bulgarian Air Force. General Manev's current interests are in organisational culture - a field in which he successfully completed the requirements for a $\mathrm{PhD}$ degree. 